\title{
Intermediate Cell Type Uveal Melanoma
}

National Cancer Institute

\section{Source}

National Cancer Institute. Intermediate Cell Type Uveal Melanoma. NCI Thesaurus. Code C7989.

Uveal melanoma characterized by the presence of intermediate cells which are similar to but smaller than epithelioid cells. 